\title{
Comparing the safety and efficacy of thoracoscopic surgery and thoracotomy for thymoma: a systematic review and meta-analysis
}

\author{
Ling Lv ${ }^{1}$, Wenya Li ${ }^{1}$, Wanfu Men ${ }^{1}$, Zhenghua Liu ${ }^{1}$, Chenggang Jiang ${ }^{2}$ \\ ${ }^{1}$ Department of Thoracic Surgery, The First Affiliated Hospital of China Medical University, Shenyang, China; ${ }^{2}$ Department of Surgical Oncology \\ and General Surgery, Key Laboratory of Precision Diagnosis and Treatment of Gastrointestinal Tumors, Ministry of Education, The First Affiliated \\ Hospital of China Medical University, Shenyang, China \\ Contributions: (I) Conception and design: L Lv; (II) Administrative support: W Li; (III) Provision of study materials or patients: W Men; (IV) \\ Collection and assembly of data: Z Liu; (V) Data analysis and interpretation: C Jiang; (VI) Manuscript writing: All authors; (VII) Final approval of \\ manuscript: All authors. \\ Correspondence to: Chenggang Jiang. Department of Surgical Oncology and General Surgery, Key Laboratory of Precision Diagnosis and Treatment \\ of Gastrointestinal Tumors, Ministry of Education, The First Affiliated Hospital of China Medical University, Shenyang 110001, China. \\ Email: Jiangcg7516@163.com.
}

Background: To systematically evaluate the efficacy of thoracoscopic surgery compared to traditional thoracotomy for thymic tumors.

Methods: We performed a literature search on computer of the PubMed, Embase, Cochrane Library, Web of Science, China Biology Medicine (CBM), WanFang, and China national knowledge infrastructure (CNKI) databases from the date of establishment of the database to April 2021, and retrieved randomized controlled trials (RCTs) and cohort studies on thoracoscopic surgery and thoracotomy with conventional open thoracic surgery. After independent screening of the literature by two assessors, the relevant data was extracted and the risk of bias in the included studies was evaluated. RevMan 5.3 software was used to perform the analysis.

Results: Five RCTs and eight cohort studies were ultimately included, with a total of 1,093 patients. The results of meta-analysis showed that compared with traditional thoracoscopic surgery, thoracoscopy had shorter surgery duration ( $\mathrm{OR}=22.2,95 \% \mathrm{CI}:-31.92,-12.52, \mathrm{P}<0.00001)$, ICU stay $(\mathrm{OR}=0.29,95 \%$ CI: $0.20,0.42, \mathrm{P}<0.00001$ ), and hospitalization time ( $\mathrm{OR}=0.531,95 \% \mathrm{CI}: 0.41,0.69, \mathrm{P}<0.00001)$ times, as well as reduced chest tube drainage time $(\mathrm{OR}=0.49,95 \% \mathrm{CI}: 0.33,0.73, \mathrm{P}=0.0004)$, less intraoperative bleeding ( $\mathrm{OR}=43.27,95 \% \mathrm{CI}:-50.94,-35.60, \mathrm{P}<0.00001)$, and a lower incidence of postoperative complications (OR $=0.19,95 \%$ CI: $0.11,0.34, \mathrm{P}<0.00001)$. However, the tumor recurrence rate was not significantly different between the two procedures ( $\mathrm{OR}=0.69,95 \% \mathrm{CI}: 0.32,1.48, \mathrm{P}=0.34)$.

Discussion: The existing evidence suggests that thoracoscopic surgery has shorter surgery duration, ICU stay time, hospitalization time, reduced thoracic tube drainage, less intraoperative bleeding, and a lower incidence of postoperative complications compared with traditional thoracotomy surgery. However, due to the poor quality of the included research, more high-quality studies need to be conducted to verify the above conclusions.

Keywords: Thymoma; surgical treatment; retrospective study; curative effect; meta-analysis

Submitted Nov 03, 2021. Accepted for publication Dec 15, 2021.

doi: $10.21037 /$ gs-21-786

View this article at: https://dx.doi.org/10.21037/gs-21-786 


\section{Introduction}

Thymoma is a common anterior mediastinal tumor originating in the thymic epithelium, accounting for approximately $20 \%$ of mediastinal tumors (1). National Cancer Institute statistics show a total population incidence of about 150/1,000, which is not statistically different between men and women. There are no special clinical symptoms in the early stage, and it is difficult for patients to perceive (2). They often observed during physical examination. In addition, thymoma often exists with paratumor syndrome, such as myasthenia gravis, erythrocyte aplastic anaemia alone, and hypopropyg lobulinemia, making the clinical disease more complex. As a potentially invasive tumor, treatment is preferred for thymoma, combined with postoperative radiotherapy or chemotherapy (3).

Thymomas are a group of mediastinal tumors derived from different thymic epithelial cells, with a total incidence of about 13/10 million. Despite its low overall incidence, it has exhibited a progressively increasing trend, and is the most common thoracic mediastinal tumor (4). At present, the most effective clinical treatment of thymoma is complete surgical resection. Traditional total thymectomy involves opening the sternum, resulting in considerable trauma and destruction of thoracic integrity as well as other postoperative complications. Meanwhile, thoracoscopic surgery [(video-assisted thoracoscopic surgery) VATS] offers reduced trauma and fewer complications; however, this procedure involves a limited intraoperative field, and resection of contralateral thymic and pericardial fat is not smooth (5).

With the continuous development of the thoracoscopic technique, thoracoscopic thymus dilatectomy has become one of the main surgical treatments for myasthenia gravis and thymoma (6). Compared with the traditional anterior median thoracotomy surgery, it has the characteristics of reduced surgical trauma, fast postoperative recovery, and less complications. At present, numerous surgical methods of thoracoscopic thoracectomy have been reported, including single and multiple operating holes through the right chest entrance, single and multiple operating holes through the left chest entrance, single and multiple operating holes through the sword protrusion, cervical chest double entry, robot surgery, etc. (7). However, there is no systematic evaluation method of myasthenia gravis surgery, and thus, the surgical approach and scope of thymectomy have become a particular research interest.

Gripp et al. (8) first reported improved symptoms following thymectomy in patients with myasthenia gravis. With the continuous development of surgical techniques, thymoma resection through the median sternum incision has become the standard surgical method for the thymus. Chao et al. (9) first performed thoracectomy, but the midmidmotomy was different from the right thoracic approach, and this operation could avoid opening the chest in patients with pleural adhesion or lung insufficiency, but only for benign lesions. In recent years, thoracoscopic right chest and transsword subthymic dilectomy has become a surgical treatment of myasthenia gravis, and is being gradually promoted. Compared with the traditional anterior median thoracotomy surgery, it has the characteristics of reduced trauma, faster postoperative recovery, and less postoperative complications (10). The surgical path of thymotomy is controversial, which is mainly reflected in laparoscopic surgery or thoracotomy. Some studies (10-12) have shown that there are differences in surgical effects in the treatment of malignant thymomas by surgical resection or lymph node dissection. Open heart surgery and thoracoscopy surgery is the surgical treatment of thymoma way, but how to choose operation method is to let the patients' families is difficult a problem, compared with the traditional open heart surgery, thoracoscope surgery is appearing in recent years, the rich clinical experience, though less open chest surgery, but thoracoscope surgery doesn't open chest, greatly reduce the patient's pain, Also can make the elderly and patients with increased tolerance of surgery in clinic is more popular than open heart surgery, but for patients with difficult to choose, especially in patients with malignant thymoma, experimenting with thoracoscope surgery, if it is found that the procedure is in violation of the principle of tumor therapy, should be timely to change professions open thoracic surgery, to remove the tumor cells.

The surgical path for thymectomy remains controversial. The classic traditional thymoma resection is median thoracectomy (TS transsternal thymectomy) (11). With the development of thoracoscopic technology in thoracic surgery, thoracoscopic surgery (VATS thymectomy) has been applied for resection. An increasing number of scholars in recent years have discussed the advantages and disadvantages of thymic thoracectomy and median thoracectomy; however, the results are inconsistent. Therefore, this study systematically evaluated the advantages and disadvantages of thoracoscopic surgery in thymomectomy in order to provide evidence for its clinical application. We present the following article in accordance 
with the PRISMA reporting checklist (available at https:// dx.doi.org/10.21037/gs-21-786).

\section{Methods}

\section{Inclusion and exclusion criteria}

The inclusion criteria were as follows: (I) study type: randomized controlled trial (RCT) or cohort study; (II) patients clinically diagnosed with thyma (note: the nationality, race, and disease course of the study subjects was not limited); (III) intervention studies where the trial group underwent thoracoscopy and the control group received traditional thoracotomy surgery; (IV) studies with outcome indicators, including the operation time, time of stay, hospitalization time, amount of intraoperative bleeding, incidence of postoperative complications, and recurrence rate. The exclusion criteria were as follows: (I) non-Chinese/ English literature; (II) repeatedly published documents; (III) studies with incomplete or missing analysis data

\section{Search strategy}

We performed a literature search of the PubMed, Embase, Cochrane Library, Web of Knowledge, CBM, WanFang, and CNKI databases from the date of establishment of the database to April 2021. We retrieved RCTs and cohort studies on thoracoscopic surgery and thoracotomy with traditional open thoracic surgery. In this study, Cochrane Library, PubMed, Web of Knowledge, Embase, CBM, CNKI, CQVIP and Wanfang were searched CECDB and other databases and related websites search. Subject words such as "Thoracoscopy", "VATS", "Thymus tumor" and so on. were retrieved as subject words and free words respectively. The literature retrieval scheme is shown in Figure 1.

\section{Literature screening, data extraction, and risk of bias evaluation of included studies}

Literature screening and data extraction were conducted and crosschecked independently by two evaluators. Differences between the two evaluators were resolved through discussion. Data extraction was performed using a predetermined data extraction table, which included the basic information of the included studies: study topic, author name, journal name, publication years, etc.; the basic characteristics of study subjects: cases, gender, age of each group, specific details of intervention measures; the key factors of bias risk evaluation; and the outcome indicators and outcome measurement data of concern. The Cochrane risk of bias evaluation tool was used to evaluate the risk of bias of the included RCTs (8), while the risk of bias of the included cohort studies was evaluated using the NewcastleOttawa Scale (NOS).

\section{Statistical analysis}

Meta-analysis was performed using the RevMan 5.3 software (USA). The mean difference (MD) was used as the effect index, and odds ratio (OR) was used as the effect quantity. The point estimates and $95 \% \mathrm{CI}$ are given for each effect quantity. The statistical heterogeneity between the study results (test level was $\alpha=0.1$ ) and the size of the heterogeneity was quantitatively determined combined with $\mathrm{I}^{2}$. If there was no statistical heterogeneity between the studies, meta-analysis was performed using a fixed effects model. For significant clinical heterogeneity, meta-analysis was performed using a random effects model after excluding the sources of heterogeneity. If the results showed significant clinical heterogeneity, subgroup or sensitivity analyses were performed.

\section{Heterogeneity analysis}

Heterogeneity between studies was assessed using $\mathrm{I}^{2}$ statistics, $25 \%, 50 \%$ and $75 \%$ representing low, medium and high heterogeneity, respectively, if $\mathrm{I}^{2}<50 \%$ and $\mathrm{P}>0.1$ between studies using fixed effect models and if $\mathrm{I}^{2}>50 \%$ and $\mathrm{P}<0.1$ from chi-square analysis showed study heterogeneity, Meta-analysis by random effects models and searched for possible heterogeneity by subgroup analysis source. The sensitivity analysis removed the included literature one by one to see whether the pooled effect values were stabled and reliabled.

\section{Results}

\section{Results of the literature search}

A total of 919 relevant documents were obtained in the preliminary search, including eight cohort studies, with a total of 1,093 patients (6-18). The CNKI, PubMed and Metetron databases were systematically searched from January 2010 to October 2021. Both Chinese and English search terms were used in the literature retrieval process. 


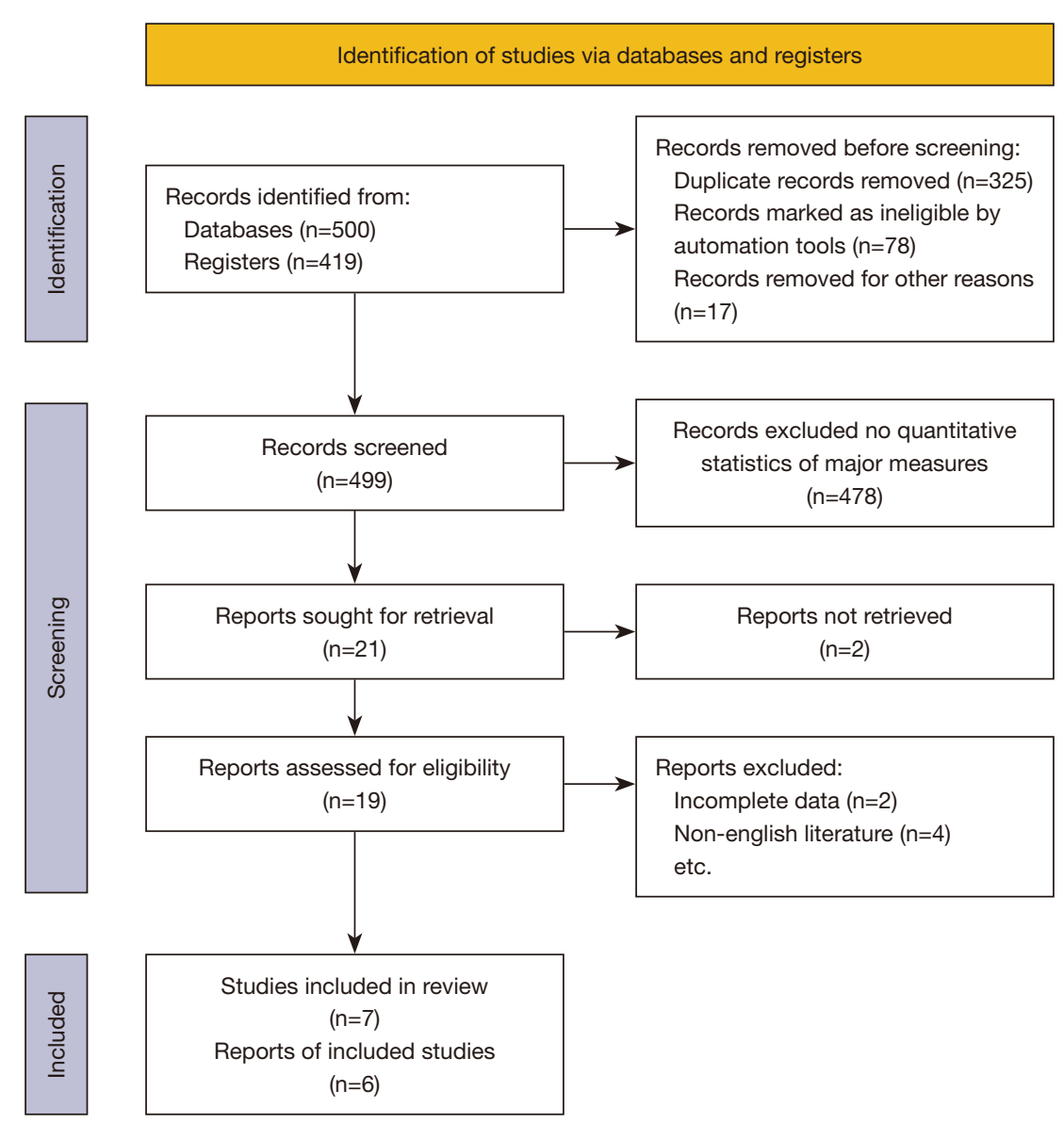

Figure 1 Literature screening process and results.

Literature retrieval was performed using a combination of subject and free words, and the references of relevant literature were manually searched after reading the full texts. The literature screening procedures and results are shown in Figure 1.

\section{Basic characteristics of the included study and bias risk assessment results}

Two researchers evaluated all of the included literature sequentially based on Cochran Literature Quality Evaluation Scale, and classified the bias risk level of each article as low risk, high risk, or uncertain risk. Data extraction included the following aspects: (I) general situation: author, group, gender, sample size, etc.; and (II) outcome index: operation time, estimated blood loss, days of hospitalization, transit chest opening rate, complications, etc. All of the studies we included were case-control studies; therefore, for the risk of bias analysis, the NOS quality score was used, and all studies were found to be high-quality studies (NOS >7). Disagreements between the evaluators were resolved through discussion or no trilateral discussion settlement. The basic characteristics of the included studies are presented in Table 1.

\section{Meta-analysis results}

\section{Operation time}

All of the included studies reported on this outcome. Metaanalysis was performed using the random effects model, and the results showed that the operation time in the thoracoscopic group was significantly shorter than that in the open chest group, and the difference was statistically significant $(\mathrm{OR}=22.2,95 \% \mathrm{CI}:-31.92,-12.52, \mathrm{P}<0.00001)$. The results of further subgroup analysis by study design showed that the operation time in the RCT subgroup was 
Table 1 Basic characteristics of the included study

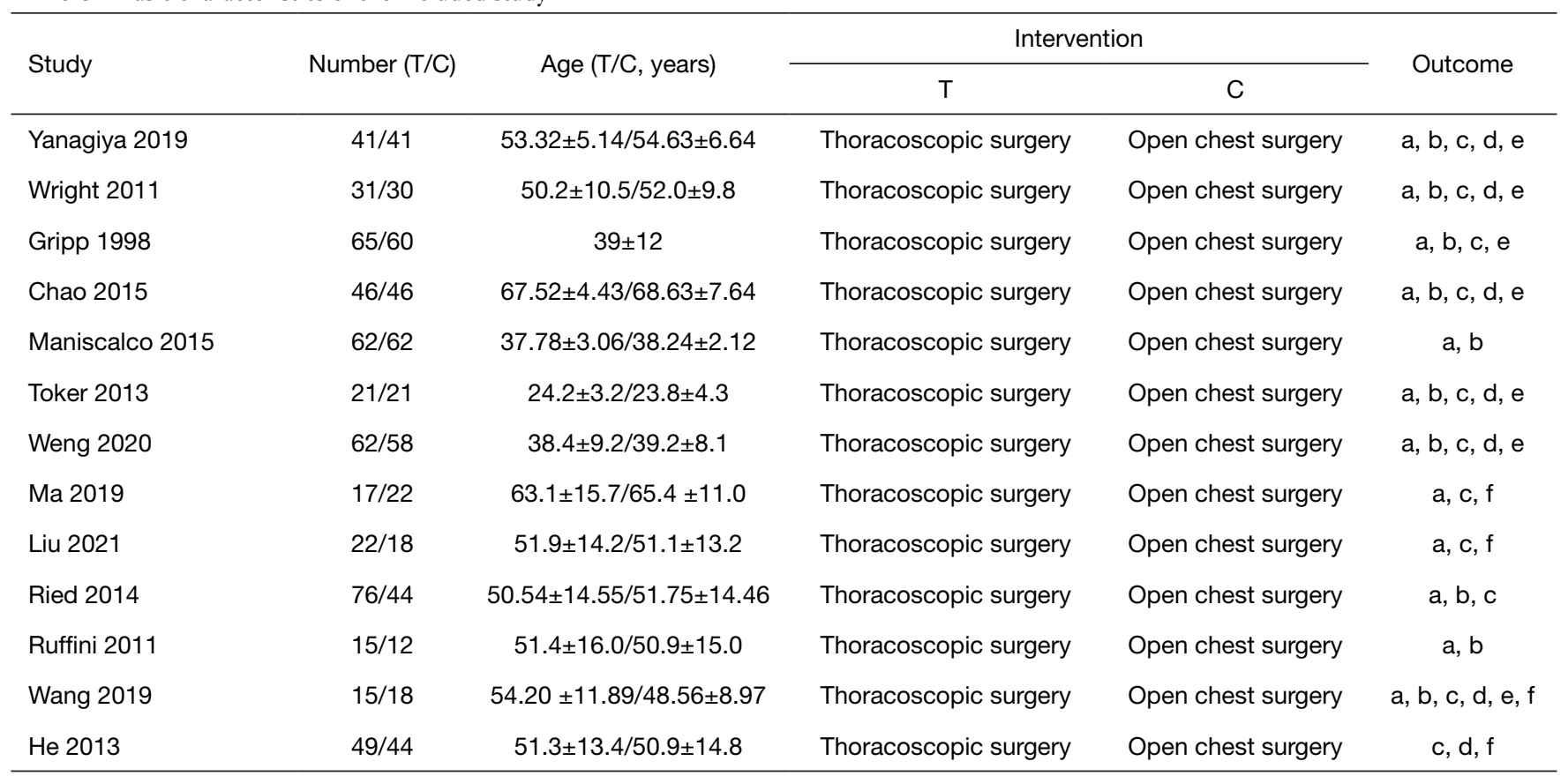

T: test group; C: control group. a, Surgery time; b, Blood bleeding during; c, Length of hospital stay; d, Drainage time of the chest tube; e, Postoperative complications; f, ICU time.

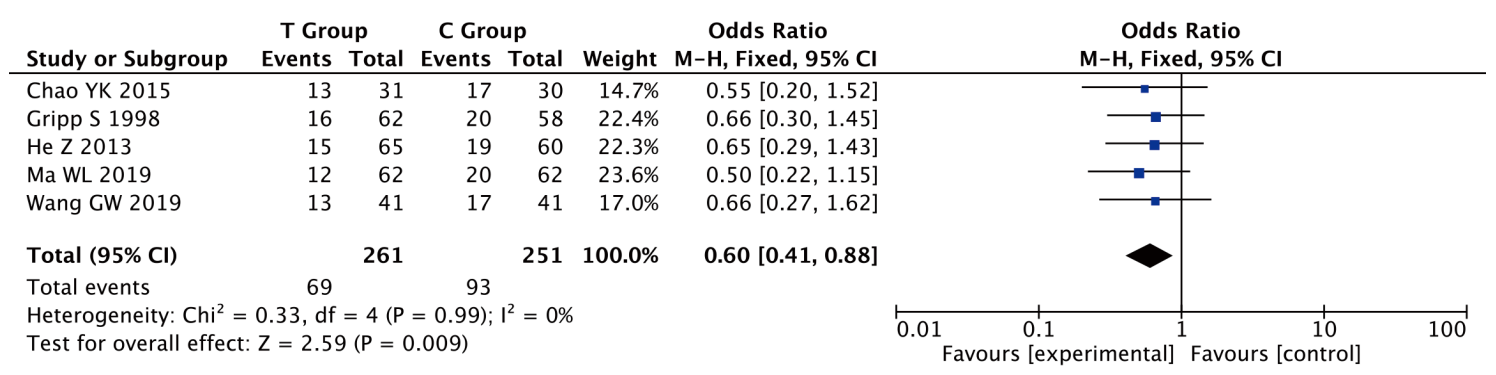

Figure 2 Meta-analysis of surgery time between thoracoscopy and thoracotomy groups.

significantly shorter than that in the thoracotomy group (OR $=0.60$, 95\% CI: 0.41, 0.88, P=0.009) (Figure 2).

\section{ICU time}

Only eight cohort studies were included. Meta-analysis was performed using the fixed effects model, and the results showed that the ICU time in the thoracoscopic group was significantly shorter than that in the open chest group, and the difference was statistically significant ( $\mathrm{OR}=0.29,95 \%$ CI: 0.20, 0.42, $\mathrm{P}<0.00001$ ) (Figure 3).

\section{Hospital stay}

Hospital stay was reported in 13 studies, including four RCTs and seven cohort studies. Meta-analysis was performed using the random effects model, and the results showed that the hospital stay in the thoracoscopic group was significantly shorter than that in the thoracotomy group $(\mathrm{OR}=0.531,95 \%$ CI: $0.41,0.69, \mathrm{P}<0.00001)$. The results of further subgroup analyses by study design showed that both the RCT and cohort study subgroups showed significantly shorter hospitalization in the thoracoscopy group than the open chest group, and the difference was statistically significant (Figure 4).

\section{Chest tube drainage time}

A total of six studies reported on this aspect, including 


\begin{tabular}{|c|c|c|c|c|c|c|c|c|c|}
\hline Study or Subgroup & \multicolumn{2}{|c|}{ T Group } & \multicolumn{2}{|c|}{ C Group } & Weight & $\begin{array}{c}\text { Odds Ratio } \\
\text { M-H, Fixed, } 95 \% \mathrm{Cl}\end{array}$ & \multicolumn{3}{|c|}{$\begin{array}{c}\text { Odds Ratio } \\
\mathrm{M}-\mathrm{H} \text {, Fixed, } 95 \% \mathrm{Cl}\end{array}$} \\
\hline Chao YK 2015 & 8 & 17 & 17 & 22 & $8.0 \%$ & $0.26[0.07,1.04]$ & & & \\
\hline Ma WL 2019 & 5 & 15 & 6 & 12 & $4.5 \%$ & $0.50[0.11,2.38]$ & & & \\
\hline Maniscalco P 2015 & 8 & 22 & 14 & 18 & $10.0 \%$ & $0.16[0.04,0.67]$ & & & \\
\hline Ruffini E 2011 & 5 & 15 & 8 & 18 & $4.9 \%$ & $0.63[0.15,2.59]$ & & & \\
\hline Toker A 2013 & 22 & 76 & 31 & 44 & $28.3 \%$ & $0.17[0.08,0.39]$ & & & \\
\hline Wang GW 2019 & 14 & 49 & 22 & 44 & $16.8 \%$ & $0.40[0.17,0.94]$ & & & \\
\hline Wright CD 2011 & 7 & 21 & 12 & 21 & $8.1 \%$ & $0.38[0.11,1.31]$ & & - & \\
\hline Yanagiya 2019 & 21 & 46 & 35 & 46 & $19.3 \%$ & $0.26[0.11,0.64]$ & & & \\
\hline Total $(95 \% \mathrm{Cl})$ & & 261 & & 225 & $100.0 \%$ & $0.29[0.20,0.42]$ & & & \\
\hline Total events & 90 & & 145 & & & & & & \\
\hline $\begin{array}{l}\text { Heterogeneity: } \mathrm{Chi}^{2} \\
\text { Test for overall effec }\end{array}$ & $\begin{array}{l}4.61, \mathrm{df} \\
Z=6.38\end{array}$ & $\begin{array}{l}=7(P \\
B(P<0\end{array}$ & $\begin{array}{l}=0.71) \\
.00001)\end{array}$ & $I^{2}=0 \%$ & & & $0.01 \quad 0.1$ & 10 & 100 \\
\hline
\end{tabular}

Figure 3 Meta-analysis of the ICU times between the thoracoscopic and open chest groups.

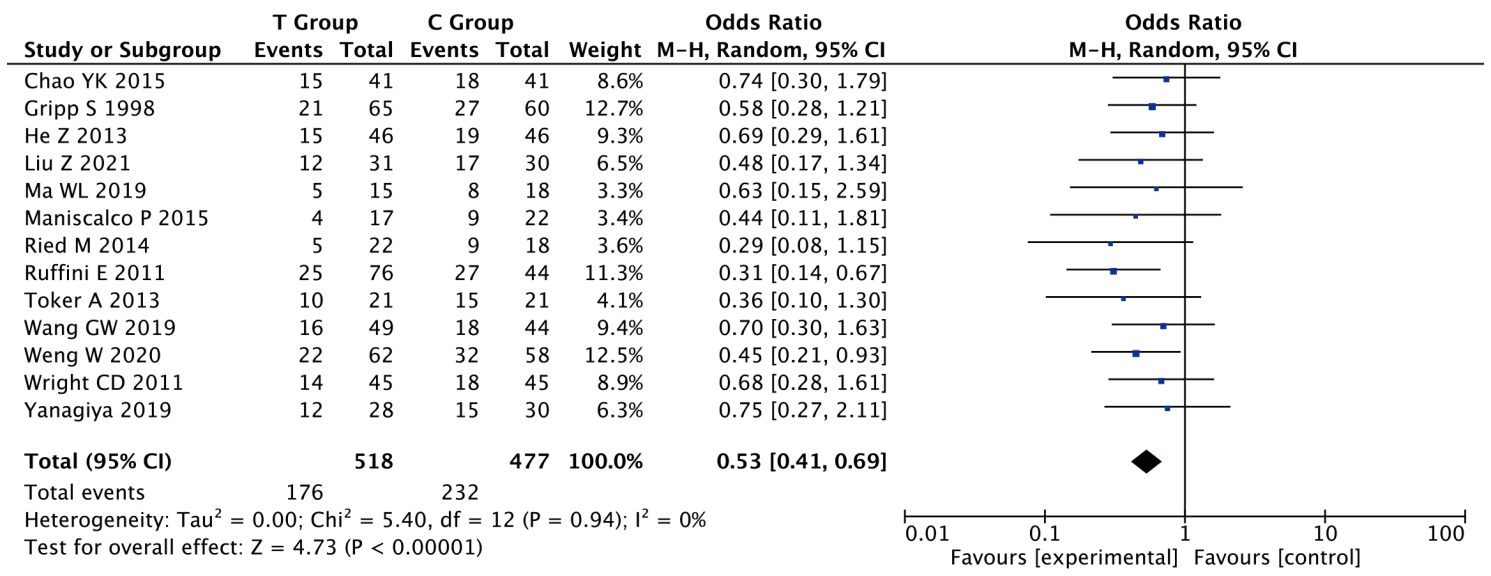

Figure 4 Meta analysis of the duration of hospitalization between thoracoscopic and open-chest groups.

three RCTs and three cohort studies. Meta-analysis was performed using the random effects model, and the results showed that the chest tube drainage time in the thoracoscopic group was significantly shorter than in the open chest group, and the difference was statistically significant $(\mathrm{OR}=0.49,95 \% \mathrm{CI}: 0.33,0.73, \mathrm{P}=0.0004)$. The results of further subgroup analysis according to a different study design showed that the thoracic tube drainage time in both the RCT and cohort study subgroups was significantly shorter in the thoracoscopy group compared to the open chest group, and the differences were statistically significant (Figure 5).

\section{Intraoperative bleeding}

In total, seven studies reported on intraoperative bleeding, including three RCTs and four cohort studies. Metaanalysis was performed using the random effects model, and the results showed that there was significantly less bleeding in the thoracoscopy group compared to the open chest group (OR $=0.53,95 \% \mathrm{CI}: 0.36,0.79, \mathrm{P}=0.002)$. The results of further subgroup analyses performed by study design showed that the RCT and cohort in all subgroups of the study had significantly less bleeding in thoracoscopy group than open chest group (Figure 6).

\section{Postoperative complications}

A total of five studies reported on postoperative complication, including three RCTs and two cohort studies. Meta-analysis was performed using the fixed effects model, and the results showed that the incidence of postoperative complications was significantly lower in the thoracoscopy group compared to the hand-open chest group $(\mathrm{OR}=0.19$, $95 \%$ CI: $0.11,0.34, \mathrm{P}<0.00001)$. Further results of subgroup analysis by study design revealed that the incidence of postoperative complications in the RCTs and cohort studies in all subgroups was markedly lower in the thoracoscopy 


\begin{tabular}{|c|c|c|c|c|c|c|c|c|c|}
\hline Study or Subgroup & \multicolumn{2}{|c|}{ T Group } & \multicolumn{2}{|c|}{ C Group } & Weight & $\begin{array}{c}\text { Odds Ratio } \\
\text { M-H, Fixed, 95\% Cl }\end{array}$ & \multicolumn{3}{|c|}{$\begin{array}{c}\text { Odds Ratio } \\
\text { M-H, Fixed, 95\% CI }\end{array}$} \\
\hline Chao YK 2015 & 9 & 21 & 12 & 21 & $9.6 \%$ & $0.56[0.17,1.91]$ & & 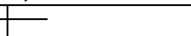 & \\
\hline Liu Z 2021 & 21 & 76 & 24 & 44 & $30.9 \%$ & $0.32[0.15,0.69]$ & & & \\
\hline Maniscalco P 2015 & 5 & 22 & 8 & 18 & $9.6 \%$ & $0.37[0.09,1.44]$ & & - & \\
\hline Ried M 2014 & 3 & 15 & 5 & 18 & $5.1 \%$ & $0.65[0.13,3.33]$ & & & \\
\hline Wang GW 2019 & 15 & 49 & 18 & 44 & $18.5 \%$ & $0.64[0.27,1.50]$ & & - & \\
\hline Weng W 2020 & 22 & 62 & 28 & 58 & $26.2 \%$ & $0.59[0.28,1.23]$ & & - & \\
\hline Total $(95 \% \mathrm{Cl})$ & & 245 & & 203 & $100.0 \%$ & $0.49[0.33,0.73]$ & & & \\
\hline Total events & 75 & & 95 & & & & & & \\
\hline $\begin{array}{l}\text { Heterogeneity: } \mathrm{Chi}^{2}= \\
\text { Test for overall effec }\end{array}$ & $\begin{array}{l}2.13, \mathrm{df} \\
\mathrm{Z}=3.53\end{array}$ & $\begin{array}{l}=5(P \\
3(P=0\end{array}$ & $\begin{array}{l}=0.83) \\
.0004)\end{array}$ & $1^{2}=0 \%$ & & & $\begin{array}{ll}0.01 & 0.1 \\
& \text { Favours [experimental] }\end{array}$ & 1 Favours [control] & $\overrightarrow{100}$ \\
\hline
\end{tabular}

Figure 5 Meta-analysis of the thoracic tube drainage time in the thoracoscopic and open chest groups.

\begin{tabular}{|c|c|c|c|c|c|c|c|c|c|c|}
\hline Study or Subgroup & \multicolumn{2}{|c|}{ T Group } & \multicolumn{2}{|c|}{ C Group } & Weight & $\begin{array}{c}\text { Odds Ratio } \\
\text { M-H, Fixed, 95\% Cl }\end{array}$ & \multicolumn{4}{|c|}{$\begin{array}{c}\text { Odds Ratio } \\
\text { M-H, Fixed, } 95 \% \mathrm{Cl}\end{array}$} \\
\hline Chao YK 2015 & 3 & 22 & 7 & 18 & $10.0 \%$ & $0.25[0.05,1.16]$ & & & 1 & \\
\hline Gripp S 1998 & 5 & 15 & 7 & 12 & $7.8 \%$ & $0.36[0.07,1.72]$ & & & & \\
\hline He Z 2013 & 4 & 15 & 8 & 18 & $8.0 \%$ & $0.45[0.10,1.99]$ & & & & \\
\hline Liu Z 2021 & 18 & 76 & 12 & 44 & $17.4 \%$ & $0.83[0.35,1.93]$ & & - & & \\
\hline Ma WL 2019 & 9 & 49 & 15 & 44 & $19.4 \%$ & $0.43[0.17,1.13]$ & & & & \\
\hline Maniscalco P 2015 & 20 & 62 & 25 & 58 & $26.3 \%$ & $0.63[0.30,1.32]$ & & & - & \\
\hline Ried M 2014 & 8 & 21 & 12 & 21 & $11.2 \%$ & $0.46[0.13,1.59]$ & & & 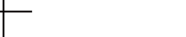 & \\
\hline Total $(95 \% \mathrm{Cl})$ & & 260 & & 215 & $100.0 \%$ & $0.53[0.36,0.79]$ & & & & \\
\hline Total events & 67 & & 86 & & & & & & & \\
\hline $\begin{array}{l}\text { Heterogeneity: } \mathrm{Chi}^{2} \\
\text { Test for overall effec }\end{array}$ & $\begin{array}{l}2.69, \mathrm{df} \\
\mathrm{Z}=3.10\end{array}$ & $\begin{array}{l}=6(P \\
(P=0\end{array}$ & $\begin{array}{l}=0.85) \\
.002)\end{array}$ & $1^{2}=0 \%$ & & & 0.01 & 0.1 [experimental] & 1 Favours [control] & 100 \\
\hline
\end{tabular}

Figure 6 Meta analysis of intraoperative bleeding in the thoracoscopic and open chest groups.

\begin{tabular}{|c|c|c|c|c|c|c|c|c|c|c|}
\hline Study or Subgroup & $\begin{array}{r}\text { T Gro } \\
\text { Events }\end{array}$ & Total & $\begin{array}{c}\text { C Gro } \\
\text { Events }\end{array}$ & up & Weight & $\begin{array}{c}\text { Odds Ratio } \\
\text { M-H, Fixed, } 95 \% \mathrm{Cl}\end{array}$ & \multicolumn{4}{|c|}{$\begin{array}{c}\text { Odds Ratio } \\
\text { M-H, Fixed, } 95 \% \mathrm{Cl}\end{array}$} \\
\hline Chao YK 2015 & 4 & 15 & 9 & 18 & $14.8 \%$ & $0.36[0.08,1.58]$ & & & E & \\
\hline Gripp S 1998 & 8 & 22 & 12 & 18 & $20.7 \%$ & $0.29[0.08,1.06]$ & & - & & \\
\hline He Z 2013 & 25 & 62 & 32 & 58 & $48.6 \%$ & $0.55[0.27,1.13]$ & & & & \\
\hline Liu Z 2021 & 6 & 21 & 9 & 21 & $15.8 \%$ & $0.53[0.15,1.92]$ & & & & \\
\hline Maniscalco P 2015 & 0 & 0 & 0 & 0 & & Not estimable & & & & \\
\hline Total $(95 \% \mathrm{Cl})$ & & 120 & & 115 & $100.0 \%$ & $0.46[0.27,0.79]$ & & & & \\
\hline Total events & 43 & & 62 & & & & & & & \\
\hline $\begin{array}{l}\text { Heterogeneity: } \mathrm{Chi}^{2}= \\
\text { Test for overall effect }\end{array}$ & $\begin{array}{l}0.88, \mathrm{df} \\
\mathrm{Z}=2.8\end{array}$ & $\begin{array}{l}=3(P= \\
5(P=0\end{array}$ & $\begin{array}{l}=0.83) \\
.004)\end{array}$ & $1^{2}=0 \%$ & & & 0.01 & 0.1 [experimental] & $\begin{array}{c}10 \\
\text { Favours [control }\end{array}$ & 100 \\
\hline
\end{tabular}

Figure 7 Meta-analysis of the incidence of postoperative complications in the thoracoscopic and open chest groups.

group than the hand-open chest group (RCT: $\mathrm{OR}=0.14$, 95\% CI: 0.06, 0.33, $\mathrm{P}<0.0001$; cohort study: $\mathrm{OR}=0.46$, 95\% CI: 0.27, 0.79, $\mathrm{P}<0.004$ ) (Figure 7).

\section{Recurrence rate}

A total of five studies reported on the recurrence rate, including three RCTs and two cohort studies. Meta-analysis was performed using the fixed effects model, and the results showed no significant difference in the recurrence rate between thoracoscopic surgery and open chest surgery. The results of further subgroup analysis according to the study design showed that the recurrence rates in both RCT and cohort studies were not significantly different $(\mathrm{OR}=0.69$, 95\% CI: 0.32, 1.48), $\mathrm{P}=0.34$ ) (Figure 8).

\section{Bias analysis}

Bias evaluation and sensitivity analysis were performed on the included research and outcome observation indicators, excluding the included literature one-by-one, and the fixed and random effects models were respectively adopted. The results were similar and showed good stability. In addition, the funnel map was analyzed, except for the operation time and intraoperative bleeding index, which indicating a large 


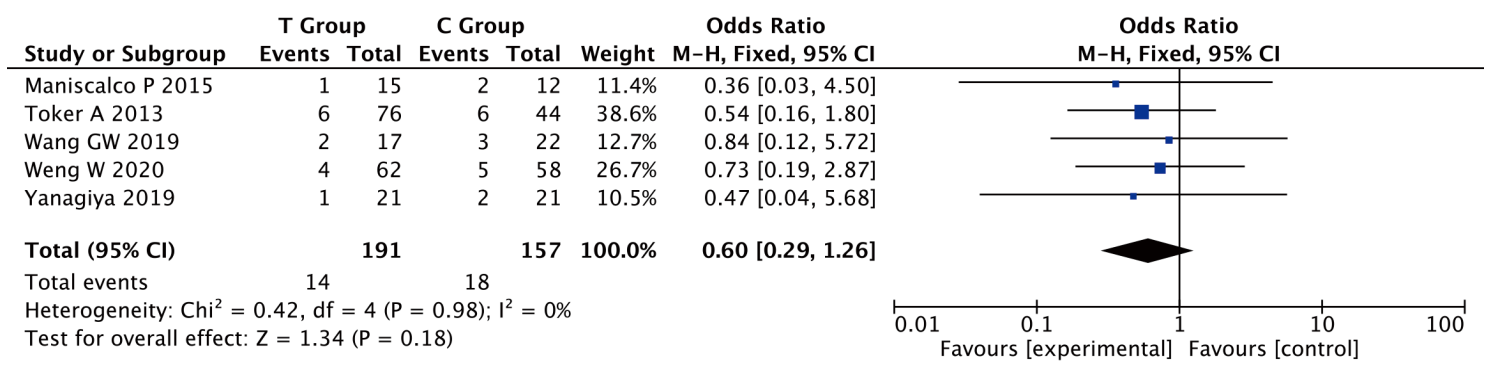

Figure 8 Meta-analysis of the tumor recurrence rates in the thoracoscopic and open-chest groups.

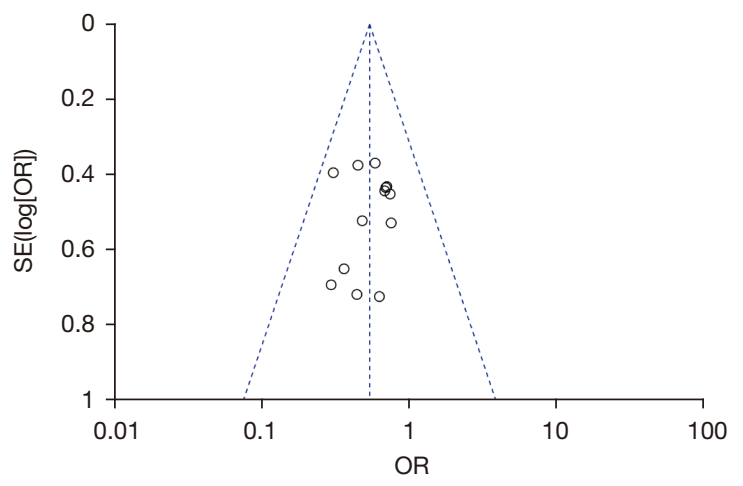

Figure 9 Funnel plot analysis of publication bias.

publication bias. However, the funnel map analysis of the remaining indicators was basically symmetrical, and the publication bias was small (Figure 9).

\section{Discussion}

Thymoma is a common mediastinal tumor with unclear etiology and pathology. Due to its potentially invasive nature and easy surrounding tissue involvement, surgical treatment is preferred after diagnosis (19). The commonly used surgical approach involves a neck incision, the posterior lateral chest incision, anterior lateral incision, and median thoracic incision (20-22). However, due to the considerable trauma of traditional open chest surgery, the damage to chest integrity, and the impact of diaphragm movement, it can easily cause serious complications, such as postoperative pulmonary lectasis, lung infection, and respiratory insufficiency. This will lead to slower patient recovery, extended hospitalization time, and increased costs (23). With the development of minimally invasive technology in the field of surgery, thoracoscopic surgery (VATS) has been increasingly applied to the surgical resection of mediastinal tumors, which has the advantages of minimal trauma and a clear surgical field. However, it is a complex and difficult operation, and has high technical requirements for operators. Hence, its effect in thymus resection remains controversial (24-26).

The present study included five RCT and eight cohort studies (6-18), and the results showed that thoracoscopic surgery could shorten the surgical, ICU, hospitalization, and thoracic tube drainage times, as well as reduce the amount of intraoperative bleeding and the incidence of postoperative complications. However, no significant differences were observed between the procedures in terms of the tumor recurrence rate. At the same time, in terms of the operation time, only the RCT subgroup showed that the thoracoscopy group was significantly better than the traditional thoracotomy group, which may be associated with the fact that degree of operative surgical proficiency and patient tumor size were related, which accounts for the considerable differences in thoracoscopic surgery times (27-30). Compared with traditional thoracotomy surgery, thoracoscopic vision recognizes the anatomy more clearly and has minimal trauma and impact on the respiratory system, and therefore, a satisfactory effect can be achieved in the treatment of thymoma (31). However, careful selection of appropriate early patients is required clinically.

Many people believe that thoracoscopic minimally invasive surgery must be better than thoracotomy, as long as malignant thymoma requires minimally invasive surgery, which is also a misunderstanding of understanding. First of all, minimally invasive surgery refers to superficial incision and radical operation for malignant thymoma. Whether under thoracotomy or endoscopy, how much lung should be cut or how much lymph nodes should be removed or how much lymph nodes should be removed. In other words, the injury in the lung is not reduced because of minimally invasive surgery (32). In addition, endoscopic 
surgery is conditional, not all malignant thymomas can be used endoscopic. Thoracoscopy may not be appropriate for a number of patients (33). (I) From the disease itself, locally advanced tumors, $\mathrm{T} 3$ and $\mathrm{T} 4$, are not suitable for thoracoscopy. (II) Tumor growth location endoscopic surgery is especially suitable for peripheral malignant thymomas. For central malignant thymomas, if the tumor can be seen under the bronchoscope, thoracoscopy is generally not suitable (34). (III) Scope of lymph nodes. The scope of lymph node metastasis is wide, and thoracoscopy is not suitable. (IV) Thoracoscopy is not suitable for patients with tumor or lymph node invasion of blood vessels and bronchus, which increases the risk of surgery. (V) Patients with malignant thymoma who cannot tolerate single-lung ventilation and cannot undergo anesthesia. Endoscopic surgery has high requirements for doctors' skills and hospital equipment (35). Some patients may have some unexpected problems during the operation and change to thoracotomy, such as massive bleeding or difficulty in operation caused by tumor adhesion. In a word, whether the patient is suitable for endoscopic surgery and whether endoscopy can be used, the thoracic surgeon will complete all the examinations before surgery, fully evaluate, and formulate the most appropriate plan according to the specific condition (36).

There were some limitations in this study that should be noted. Firstly, only five RCTs (6-18) were included, all of which were Chinese studies. Therefore, a high risk of bias exists. Meanwhile, the included cohort studies were limited by study design, and the reliability of the meta-analysis is poor (37). Secondly, the tumor status (pathological grade, clinical stage) of each study, which may cause bias to the results. Thirdly, all of the included studies were not blinded when considering the clinical and functional results, and thus, observer bias is an important limitation.

Taken together, the current evidence shows that compared to traditional thoracotomy, thoracoscopic surgery shortens the surgical, ICU stay, hospitalization, and thoracic tube drainage times. In addition, it reduces intraoperative bleeding and the incidence of complications (38-40). However, the quality of the included studies was limited; thus, large sample, high-quality RCTs are needed to verify the above conclusions.

\section{Acknowledgments}

Funding: This work was supported by the General Project of Liaoning Provincial Education Department (No.
JCZR2020004).

\section{Footnote}

Reporting Checklist: The authors have completed the PRISMA reporting checklist (available at https://dx.doi. org/10.21037/gs-21-786).

Conflicts of Interest: All authors have completed the ICMJE uniform disclosure form (available at http://dx.doi.org/ gs-21-786). The authors have no conflicts of interest to declare.

Ethical Statement: The authors are accountable for all aspects of the work in ensuring that questions related to the accuracy or integrity of any part of the work are appropriately investigated and resolved.

Open Access Statement: This is an Open Access article distributed in accordance with the Creative Commons Attribution-NonCommercial-NoDerivs 4.0 International License (CC BY-NC-ND 4.0), which permits the noncommercial replication and distribution of the article with the strict proviso that no changes or edits are made and the original work is properly cited (including links to both the formal publication through the relevant DOI and the license). See: https://creativecommons.org/licenses/by-nc-nd/4.0/.

\section{References}

1. Sehitogullari A, Nasır A, Anbar R, et al. Comparison of perioperative outcomes of videothoracoscopy and robotic surgical techniques in thymoma. Asian J Surg 2020;43:244-50.

2. Vita ML, Tessitore A, Cusumano G, et al. Recurrence of thymoma: re-operation and outcome. Ann Ital Chir 2007;78:375-6.

3. Li J, Liu Q, Zheng Z, Li S. Prolonged survival time with surgical therapy in different types of thymoma: an analysis based on Surveillance Epidemiology and End Results Database. Transl Cancer Res 2020;9:5893-99.

4. Yu L, Zhang XJ, Ma S, et al. Thoracoscopic thymectomy for myasthenia gravis with and without thymoma: a singlecenter experience. Ann Thorac Surg 2012;93:240-4.

5. Manoly I, Whistance RN, Sreekumar R, et al. Early and mid-term outcomes of trans-sternal and video-assisted thoracoscopic surgery for thymoma. Eur J Cardiothorac Surg 2014;45:e187-93. 
6. Yanagiya M, Matsumoto J, Kawahara T, et al. Influence of Smoking and Histologic Subtype on Developing Extrathymic Malignancy in Thymoma Patients. Ann Thorac Surg 2019;107:1532-9.

7. Wright CD. Stage IVA thymoma: patterns of spread and surgical management. Thorac Surg Clin 2011;21:93-7, vii.

8. Gripp S, Hilgers K, Wurm R, et al. Thymoma: prognostic factors and treatment outcomes. Cancer 1998;83:1495-503.

9. Chao YK, Liu YH, Hsieh MJ, et al. Long-term outcomes after thoracoscopic resection of stage I and II thymoma: a propensity-matched study. Ann Surg Oncol 2015;22:1371-6.

10. Maniscalco P, Tamburini N, Quarantotto F, et al. Longterm outcome for early stage thymoma: comparison between thoracoscopic and open approaches. Thorac Cardiovasc Surg 2015;63:201-5.

11. Toker A, Erus S, Ziyade S, et al. It is feasible to operate on pathological Masaoka stage I and II thymoma patients with video-assisted thoracoscopy: analysis of factors for a successful resection. Surg Endosc 2013;27:1555-60.

12. Weng W, Li X, Meng S, et al. Video-assisted thoracoscopic thymectomy is feasible for large thymomas: a propensitymatched comparison. Interact Cardiovasc Thorac Surg 2020;30:565-72.

13. Ma WL, Lin CC, Hsu FM, et al. Clinical Outcomes of Up-front Surgery Versus Surgery After Induction Chemotherapy for Thymoma and Thymic Carcinoma: A Retrospective Study. Clin Lung Cancer 2019;20:e609-18.

14. Liu Z, Yang R. Comparison of Subxiphoid and Intercostal Uniportal Thoracoscopic Thymectomy for Nonmyasthenic Early-Stage Thymoma: A Retrospective Single-Center Propensity-Score Matching Analysis. Thorac Cardiovasc Surg 2021;69:173-80.

15. Ried M, Potzger T, Sziklavari Z, et al. Extended surgical resections of advanced thymoma Masaoka stages III and IVa facilitate outcome. Thorac Cardiovasc Surg 2014;62:161-8.

16. Ruffini E, Filosso PL, Mossetti C, et al. Thymoma: inter-relationships among World Health Organization histology, Masaoka staging and myasthenia gravis and their independent prognostic significance: a single-centre experience. Eur J Cardiothorac Surg 2011;40:146-53.

17. Wang GW, Tao T, Li CK, et al. Comparison between thoracoscopic and open approaches in thymoma resection. J Thorac Dis 2019;11:4159-68.

18. He Z, Zhu Q, Wen W, et al. Surgical approaches for stage I and II thymoma-associated myasthenia gravis: feasibility of complete video-assisted thoracoscopic surgery (VATS) thymectomy in comparison with trans-sternal resection. J Biomed Res 2013;27:62-70.

19. Infante M, Benato C, Giovannetti R, et al. VATS thymectomy for early stage thymoma and myasthenia gravis: combined right-sided uniportal and left-sided three-portal approach. J Vis Surg 2017;3:144.

20. Marulli G, Comacchio GM, Rea F. Video assisted thoracic surgery (VATS) for recurrent thymoma. Ann Cardiothorac Surg 2015;4:540-4.

21. Raza A, Woo E. Video-assisted thoracoscopic surgery versus sternotomy in thymectomy for thymoma and myasthenia gravis. Ann Cardiothorac Surg 2016;5:33-7.

22. O'Sullivan KE, Kreaden US, Hebert AE, et al. A systematic review of robotic versus open and video assisted thoracoscopic surgery (VATS) approaches for thymectomy. Ann Cardiothorac Surg 2019;8:174-93.

23. Toker A. Standardized definitions and policies of minimally invasive thymoma resection. Ann Cardiothorac Surg 2015;4:535-9.

24. De Rosa A, Fornili M, Maestri Tassoni M, et al. Thymoma-associated myasthenia gravis: Clinical features and predictive value of antiacetylcholine receptor antibodies in the risk of recurrence of thymoma. Thorac Cancer 2021;12:106-13.

25. Li JF, Hui BG, Li X, et al. Video-assisted thoracic surgery for thymoma: long-term follow-up results and prognostic factors-single-center experience of 150 cases. J Thorac Dis 2018;10:291-7.

26. Pennathur A, Qureshi I, Schuchert MJ, et al. Comparison of surgical techniques for early-stage thymoma: feasibility of minimally invasive thymectomy and comparison with open resection. J Thorac Cardiovasc Surg 2011;141:694-701.

27. Tianci C, Shen Z, Chen S, et al. Median sternotomy versus minimally invasive thymectomy for early-stage thymoma: A systematic review and meta-analysis protocol. Medicine (Baltimore) 2019;98:e18359.

28. Zahid I, Sharif S, Routledge T, et al. Video-assisted thoracoscopic surgery or transsternal thymectomy in the treatment of myasthenia gravis? Interact Cardiovasc Thorac Surg 2011;12:40-6.

29. Pupovac SS, Newman J, Lee PC, et al. Intermediate oncologic outcomes after uniportal video-assisted thoracoscopic thymectomy for early-stage thymoma. J Thorac Dis 2020;12:4025-32.

30. Rusidanmu A, Feng M, Xu J, et al. Trans-sternotomy versus video-assisted thoracic surgery for early- 
stage thymoma patients: a meta-analysis. Gland Surg 2020;9:342-51.

31. Toker A, Erus S, Ozkan B, et al. Does a relationship exist between the number of thoracoscopic thymectomies performed and the learning curve for thoracoscopic resection of thymoma in patients with myasthenia gravis? Interact Cardiovasc Thorac Surg 2011;12:152-5.

32. Moorjani N, Khan O, Brown I, et al. Synchronous thymoma and lung carcinoma resected via median sternotomy with VATS guidance. Thorac Cardiovasc Surg 2007;55:271-2.

33. Agasthian T, Lin SJ. Clinical outcome of video-assisted thymectomy for myasthenia gravis and thymoma. Asian Cardiovasc Thorac Ann 2010;18:234-9.

34. Hirai K, Ibi T, Bessho R, et al. Video-assisted thoracoscopic thymectomy (VAT-T) with lateral thoracotomy for stage II and III thymoma. Ann Thorac Cardiovasc Surg 2013;19:79-82.

35. Qi K, Wang B, Wang B, et al. Video-assisted thoracoscopic surgery thymectomy versus open thymectomy in patients with myasthenia gravis: a meta-analysis. Acta Chir Belg 2016;116:282-8.

36. Xie A, Tjahjono R, Phan K, et al. Video-assisted

Cite this article as: $\mathrm{Lv} \mathrm{L}, \mathrm{Li}$ W, Men W, Liu Z, Jiang C. Comparing the safety and efficacy of thoracoscopic surgery and thoracotomy for thymoma: a systematic review and metaanalysis. Gland Surg 2021;10(12):3378-3388. doi: 10.21037/gs21-786 thoracoscopic surgery versus open thymectomy for thymoma: a systematic review. Ann Cardiothorac Surg 2015;4:495-508.

37. Nguyen GT, Nguyen TN, Nguyen NV, et al. Videoassisted thoracoscopic thymectomy for thymoma: a single-center experience. Asian Cardiovasc Thorac Ann 2018;26:207-11.

38. Kumazawa S, Ishibashi H, Takahashi K, et al. Transcervical excision of thymoma and video-assisted thoracoscopic extended thymectomy (VATET) for ectopic cervical thymoma with myasthenia gravis: report of a case. Gen Thorac Cardiovasc Surg 2016;64:752-4.

39. Nguyen TG, Nguyen NT, Nguyen VN, et al. Videoassisted thoracoscopic surgery for myasthenia gravis with thymoma: A six-year single-center experience. Asian J Surg 2021;44:369-73.

40. Ye B, Tantai JC, Ge XX, et al. Surgical techniques for early-stage thymoma: video-assisted thoracoscopic thymectomy versus transsternal thymectomy. J Thorac Cardiovasc Surg 2014;147:1599-603.

(English Language Editor: A. Kassem) 